\title{
The effects of material formulation and manufacturing process on mechanical and thermal properties of epoxy/clay nanocomposites
}

H. Salam ${ }^{1,2}$, Y. Dong ${ }^{1 *}$, I. J. Davies ${ }^{1}$ and A. Pramanik ${ }^{1}$

1 Department of Mechanical Engineering, School of Civil and Mechanical Engineering, Curtin University, GPO Box U1987, Perth, WA 6845, Australia

2 Department of Mechanical Engineering Education, Indonesia University of Education, Bandung 40153, West Java, Indonesia

*Corresponding author: Yu Dong, Department of Mechanical Engineering, School of Civil and Mechanical Engineering, Curtin University, GPO Box U1987, Perth, WA 6845, Australia (Tel: +61 89266 9055; Fax: +61 89266 2681; e-mail: Y.Dong@curtin.edu.au)

\begin{abstract}
A holistic study was conducted to investigate the combined effect of three different pre-mixing processes, namely mechanical mixing, ultrasonication and centrifugation, on mechanical and thermal properties of epoxy/clay nanocomposites reinforced with different platelet-like montmorillonite (MMT) clays (Cloisite $\mathrm{Na}^{+}$, Cloisite $10 \mathrm{~A}$, Cloisite 15 or Cloisite 93A) at clay contents of 3-10 wt\%. Furthermore, the effect of combined pre-mixing processes and material formulation on clay dispersion and corresponding material properties of resulting composites was investigated using Xray diffraction (XRD), transmission electron microscopy (TEM), scanning electron microscopy (SEM), flexural and Charpy impact tests, Rockwell hardness tests and
\end{abstract}


differential scanning calorimetry (DSC). A high level of clay agglomeration and partially intercalated/exfoliated clay structures were observed regardless of clay type and content. Epoxy/clay nanocomposites demonstrate an overall noticeable improvement of up to $10 \%$ in the glass transition temperature $\left(T_{g}\right)$ compared to that of neat epoxy, which is interpreted by the inclusion of MMT clays acting as rigid fillers to restrict the chain mobility of epoxy matrices. The impact strength of epoxy/clay nanocomposites was also found to increase by up to $24 \%$ with the addition of $3 \mathrm{wt} \%$ Cloisite $\mathrm{Na}^{+}$clays. However, their flexural strength and hardness diminished when compared to those of neat epoxy, arising from several effects including clay agglomeration, widely distributed microvoids and microcracks as well as weak interfacial bonding between clay particles and epoxy matrices, as confirmed from TEM and SEM results. Overall, it is suggested that an improved technique should be used for the combination of pre-mixing processes in order to achieve the optimal manufacturing condition of uniform clay dispersion and minimal void contents.

Keywords Mechanical mixing. Ultrasonication- Centrifugation- Montmorillonite (MMT) clays· Nanocomposites

\section{Introduction}

Excellent mechanical and adhesive properties of epoxy resin have played an important role in the development of epoxy/clay nanocomposites [1]. A wide range of applications in epoxy systems has attracted significant interests from researchers to develop epoxy/clay nanocomposites for automotive and aerospace applications, shipbuilding and electronic devices [2]. Such materials can also work as casting resins, adhesives and high-performance coatings for tribological applications such as 
slide bearings and calendering roller covers [3]. Notwithstanding that highly crosslinked epoxy matrices are known to exhibit high stiffness and strength, their lack of plastic deformation (i.e. brittle behavior) is a major drawback for many applications $[4,5]$.

In recent years, epoxy nanocomposites reinforced with montmorillonite (MMT) clays have drawn significant attention within the research community, especially in the aspect of the development of manufacturing techniques for polymer/clay nanocomposites [3, 6-10]. Furthermore, mechanical and thermal properties of polymer/clay nanocomposites may be significantly influenced by the material formulation associated with the wettability of clay particles and interfacial bonding between clay fillers and polymer matrices [3, 11-12]. For example, Alexandre and Dubois [3] stated that clays have been frequently used as nanofillers due to their ability to improve material performances, such as to increase strength and modulus, improve heat resistance, decrease gas permeability and exhibit excellent flame retardancy at very low clay contents with cost-competitiveness. On the other hand, Chen and Yang [6] reported that the modification of interlayer spacing of natural clays with onium ions could enhance interlayer spacing, and thus increasing the glass transition temperature of resulting nanocomposites. In addition, widespread investigations have been made to evaluate the effect of clay inclusions on tensile strength [13-16], Young's modulus [17-18], tensile creep behavior [19], flexural properties [20-22], heat resistance [23-24], barrier performance [25] and flame retardancy [26] of nanocomposites.

In epoxy/clay nanocomposite systems, physical and thermal properties are known to be influenced not only by the wettability of clay structures in term of their exfoliation but also the type of curing agent and curing temperature [27-31]. Kornmann et al. [32] studied the influence of curing agent's reactivity on resulting structures of epoxy/clay nanocomposites. It was found that curing agents with low reactivity such as aliphatic 
tended to produce an exfoliated structure with better clay dispersion and higher flexural modulus of composites. Consistently, Azeez et al. [27] also noted that curing agent's reactivity affected the exfoliation structure in epoxy/clay nanocomposite systems. In contrast, Kong and Park [33] and Wang et al. [34] demonstrated that epoxy/clay nanocomposites based on a diglycidyl ether of bisphenol-A (DGEBA)/ 1, 3-phenylendiamine (PDA) system tended to produce an intercalated clay structure owing to the high reactivity of aromatic diamine curing agent. As a consequence, the synthesis of well-dispersed clay structures in epoxy nanocomposites can be prepared by controlling the curing speed of interlayer areas to be faster than that of external layer counterparts.

More critically, non-homogeneous clay dispersion and existence of voids due to air entrapment are formidable issues required to be tackled in order to successfully manufacture epoxy nanocomposites as such issues can adversely affect their resulting mechanical properties [10-11, 35]. The pre-mixing becomes an importance step to disperse clay fillers into polymer matrices. Shear mixing and ultrasonication processes are currently the common techniques that widely used on particle/filler dispersion process $[6-7,10-11,13-14,15,27-29,30,36-37,38]$. In the shear mixing process, fluid shear force and impacts among clay-clay particles as well as impellerclay particles owing to agitation of impeller break up clay aggregates into fine particles [39]. The illustration of fluid flow in shear mixing can be seen in Fig. 1.a. This physical process can suspend and disperse clay particles to make a slurry. According to Atiemo-Obeng et al. [39], there are six key points to achieve good wettablity of solid-liquid mixing, which are operation methods, phases, properties of solid and liquid phases, unit operation, vessel geometry and mixing parameters. Shear mixing technique have been employed to obtain homogenous clay dispersion or clay wettability [13, 28, 37] and good interfacial bonding between clay nanofillers and 
polymer matrices [40]. Moreover, Gupta et al. [38] reported that exfoliated structures resulted in increased tensile modulus, which was achieved by both mechanical mixing and shear mixing techniques. However, the presence of weak interfacial bonding appeared to decrease both tensile and compressive strengths. Additionally, Park et al. [41] found that the use of high shear forces during mixing could break up clay agglomerates and separate layered clay platelets into exfoliated structures, which, however, was at the expense of reduced tensile strength and modulus due to air entrapment. Yasmin et al. [42] showed that much higher shear mixing speeds could simultaneously produce foam mixtures with the increased viscosity. Both aspects were detrimental to mechanical properties of nanocomposites. Accordingly, it is evident that both shear mixing and mechanical mixing can potentially be used as an alternative technique to break up clay aggregates in order to achieve homogenous clay dispersion.

On the other hand, the effect of ultrasonication technique is also clearly demonstrated on clay dispersion in polymer matrices, which has been proven to be highly effective for the dispersion of fine fillers within polymer matrices [21, 42]. In the sonication process, when sound waves propagate into the liquid, ultrasound cavities liked bubbles take place (Fig. 1b) [43, 44]. The bubbles motion can produce high pressure in the solution that is inserted between particles and separate or increase layer interplanar distances. Ultrasonic parameters impacting ultrasounds cavities are frequency, intensity, temperature, solvent viscosity, vapour pressure, surface tension, bubble gases and external pressure [43]. In line with this, current results [45] indicated that sonication time and energy played an important role in reducing the size of clay clusters. Moreover, it was highlighted that high-quality clay dispersion could be obtained through the combination of highest power intensity (i.e. 100\%) and shorter sonication time (i.e. less than 20 minutes) [46-48]. On the other hand, Dean et 
al. [49] investigated the effect of ulrasonication technique on mechanical and thermal properties of epoxy/clay nanocomposites. It was found that clay wettability was improved in the sonicated samples compared to shear mixed counterparts. Moreover, flexural strength of bath sonicated nanocomposite samples at the clay content of 1 wt $\%$ was increased to over $100 \%$ and $27 \%$ as opposed to those of neat epoxy and shear mixed nanocomposite counterparts, respectively. Meanwhile, glass transition and thermal degradation characteristics of resulting nanocomposite materials via ultrasoncation appeared to be quite similar to those of neat epoxy and shear-mixed nanocomposites with increasing the clay content.

Alternatively, centrifugal technique can be used to disperse clay particles into polymer matrices [8, 50-52]. Generally, centrifugal process is employed to separate mixtures. Rotational movement with a high speed of the centrifugal tube produces a centrifugal force leading to the particle movement (Fig. 1.c). Processing parameters such as rotor speed, suration of rotation and temperature process can highly influence the centrifugal process [53]. As mentioned by Saber-Samandari et al. [50], rotor speed is regarded as a quite influential parameter for resulting material properties of epoxy/clay nanocomposites. According to their results, the highest elastic modulus of epoxy/clay nanocomposites was found at the lowest rotor speed of $3000 \mathrm{rpm}$ with a mix of intercalated/exfoliated clay structures. Using the centrifugal mixing, Kabakov et al. [51] revealed that only intercalated clay structures occurred in size of 500-1000 $\mathrm{nm}$ according to the SEM observation. High shear force has also been mentioned to be effective in separating multi-layers of clay platelets. Further investigation was undertaken by Agubra et al. [52] to manufacture epoxy/E-glass fibre/clay nanocomposites, using combined magnetic and centrifugal mixing, and subsequent roll milling. Such a combined mixing approach gave rise to exfoliated clay structures within epoxy matrices as evidenced by TEM results. Moreover, Ianchis et al. [8] used 
centrifugal vacuum mixing to reduce the amount of air entrapment, arising from roll mill mixing. A higher storage modulus and stiffness were obtained for prepared nanocomposites, along with an increase of up to $40 \%$ for $T_{g}$ when compared to those of neat epoxy. Such improvements could be ascribed to the removal of air bubbles.

In light of the results mentioned so far, current study aims to examine the effect of material formulation and combined pre-mixing methods (i.e. mechanical mixing, ultrasonication and centrifugation) on mechanical and thermal properties of epoxy/clay nanocomposites using a solution casting method. Two different types of MMT clay fillers based on pristine and organomodified clays with different organic modifiers, various interlayer spacing values and clay contents were selected to evaluate the morphological structure and mechanical and thermal properties of epoxy/clay nanocomposites. It is anticipated to eventually provide useful guidance on the further optimisation of material formulation and manufacturing process for epoxy/clay nanocomposites.

\section{Experiment procedures}

\subsection{Materials}

Diglycidyl ether of bisphenol-A (DGEBA) resin and isophronediamine (IPDA) curing agent (L13 kit) were supplied by Adhesive Engineering Pty, NSW Australia with a recommended mix ratio of 100:22.87. Two different types of MMT clay fillers, denoted as unmodified clays (Cloisite $\mathrm{Na}^{+}$) and organomodified clays (Cloisite 10A, Cloisite 15 and Cloisite 93A) were purchased from BYK-Chemie GmbH, Germany with organic modifiers, interlayer spacings $\left(d_{001}\right)$ and cation exchange capacities (CEC) listed in Table 1. 


\subsection{Manufacture of epoxy/clay nanocomposites}

Manufacture of epoxy/clay nanocomposites was started by pre-heating DGEBA resin (100 gram) at $80{ }^{\circ} \mathrm{C}$ in order to reduce the epoxy viscosity. Desired amounts of clay particles in range from 3 to $10 \mathrm{wt} \%$ were poured slowly and hand mixed into epoxy with a glass rod until all clay immersed. Clay fillers were pre-dried under vacuum at $80{ }^{\circ} \mathrm{C}$ for $24 \mathrm{~h}$. Following this, DGEBA/clay mixture underwent shear mixing with a rotor speed of $510 \mathrm{rpm}$ for $1 \mathrm{~h}$ using IKA RW20 mixer attached to a high shear impeller to reduce clay agglomeration. Further, the mixture was poured into a polyethylene sealed bag. This was followed by the ultrasonication (Model ELMA Ti$\mathrm{H}-5)$ at $25 \mathrm{kHz}$ with a sweep mode and $100 \%$ power intensity at $50{ }^{\circ} \mathrm{C}$ for $45 \mathrm{~min}$ for finer clay dispersion. After poured into a centrifugal tube, the mixture was then placed in a centrifugal machine (Eppendorf centrifuge 5810R) with a rotor speed of 4000 rpm for 30 min at $40{ }^{\circ} \mathrm{C}$ to remove entrapped air bubbles. IPDA curing agent was added to epoxy/clay mixture (previously allowed to cool down to ambient temperature) using thorough hand mixing for $5 \mathrm{~min}$. It was followed by the ultrasonication that was performed at $25 \mathrm{kHz}$ with a degas mode and $100 \%$ power intensity for 15 min at ambient temperature. The mixed slurry was subsequently poured into mold cavities for the preparation of mechanical testing samples. Finally, all prepared nanocomposite samples were cured at ambient temperature for 3 days. The entire preparation procedure is illustrated in Fig. 2.

\subsection{Material testing and characterisation}

To investigate the effect of manufacturing process and clay types on mechanical properties, flexural tests were carried out based on a three-point bending rig on a universal testing machine (Lloyds EZ50) according to ASTM D790. The samples in 
size of $127 \times 12.7 \times 3.2 \mathrm{~mm}$ were supported using a span of $51 \mathrm{~mm}$ and loaded with a crosshead speed of $31.37 \mathrm{~mm} / \mathrm{min}$. Charpy impact tests (V notch) were carried out based on ASTM D6110 with a pendulum arm of $225 \mathrm{~mm}$, pendulum energy of $0.5 \mathrm{~J}$ and a span of 101.6 mm using a Zwick D-7900 impact tester. In addition, Rockwell hardness scale E (HRE) tests were conducted in accordance with ASTM D765 with an indenter of $3.175 \mathrm{~mm}$ and load of $980.7 \mathrm{~N}$ on an Avery 6470 Rockwell hardnesstesting machine.

X-ray diffraction (XRD) patterns were obtained to investigate intercalated clay structures within epoxy/clay nanocomposites at a diffraction angle $2 \theta$ from 2 to $10^{\circ}$ on a PANalytical EMPYREAN/PIXcel ${ }^{3 \mathrm{D}} \mathrm{X}$-ray diffractometer using $\mathrm{CuK} \alpha$ radiation (wave length $\lambda=0.1541 \mathrm{~nm}$ ) at $40 \mathrm{kV}$ and $40 \mathrm{~mA}$ (scanning step time of 296 second/step and step size at $0.02^{\circ}$ ). A JEOL 2100 transmission electron microscope (TEM) was used to study clay morphological structures within epoxy matrices at an accelerating voltage of $120 \mathrm{kV}$. The TEM samples (average thickness $100 \mathrm{~nm}$ ) were cut with a glass knife using a Leica EM UC6 ultramicrotome with sliced samples collected on 300 mesh copper grids.

Fracture surfaces of flexural testing samples (coated with a $5 \mathrm{~nm}$ layer of platinum to avoid charging effects) were investigated by scanning electron microscopy (SEM) using a Zeiss Neon 40EsB at an accelerating voltage of $15 \mathrm{kV}$. Differential scanning calorimetry (DSC) was performed on a Perkin-Elmer DSC6000 thermal analyser. 10$15 \mathrm{mg}$ samples were heated from -80 to $100{ }^{\circ} \mathrm{C}$ at a hearing/cooling rate of $10^{\circ} \mathrm{C} / \mathrm{min}$ under a nitrogen flow of $20 \mathrm{~mL} / \mathrm{min}$. 


\section{Result and discussion}

\subsection{XRD analysis}

XRD patterns of platelet-like clays and their corresponding nanocomposites are presented in Fig. 3. Calculated d-spacing values of as-received organoclays and epoxy nanocomposites with different clay types and contents are shown in Table 2. Overall, the addition of organoclays into epoxy matrices was found to increase $d$-spacing values for three types of clays, namely Cloisite $\mathrm{Na}^{+}$, Cloisite $10 \mathrm{~A}$ and Cloisite 93A. However, the $d$-spacing value of epoxy/Cloisite 15 clay nanocomposites remained at a similar level to that of as-received Cloisite 15. It has been shown that epoxy nanocomposites reinforced with Cloisite $\mathrm{Na}^{+}$, Cloisite 10A, Cloisite 15 and Cloisite 93A exhibit increases in interlayer spacing values of approximately 33, 44, 6 and $40 \%$, respectively. This implies that clay intercalation at different levels took place during the manufacture of epoxy/clay nanocomposites owing to the effect of cation exchange capacity (CEC) for different clay types and curing agents [32, 33, 55]. More interestingly, the $d$-spacing values of epoxy nanocomposites reinforced with organomodified clays (i.e. Cloisite 15, Cloisite 10A and Cloisite 93A) have similar values close to $3.5 \mathrm{~nm}$. It is worth noting that DGEBA molecules can only be swollen into clay interlayer areas in order to increase the $d$-spacing values.

Based on XRD results depicted in Fig 3, XRD peaks of epoxy/clay nanocomposites are shifted to lower diffraction angles with a clear sign of intercalated clay structures. From the manufacturing point of view in the combination of three different premixing method, this phenomenon might occur at the processing stage of mechanical mixing, during which large clay aggregates are broken up into fine particles and DGEBA molecules are diffused into interlayer areas of clay platelets. In the secondary ultrasonication with the presence of DGEBA infusion, ultrasound waves 
could propagate epoxy liquids to cause their high-pressure movement into multilayers of clay platelets, thus further enhancing the separation of platelet layers. The results of intercalated clay structures can arise from the influence of non-optimum processing parameters, namely mechanical mixing parameters (i.e. mixing speed, time and temperature) and ultrasonic parameters (i.e. frequency, power intensity, temperature and time). The selection of those parameters may not be appropriate to substantially break up clay platelets and facilitate the penetration into clay interlayers. The other point worth mentioning is that molecular structure and chemical properties of epoxy resin also plays an essential part in final morphological structures of resulting nanocomposites, as previously stated by Becker et al. [55]. The length of epoxy molecules and number of molecular chains are limited, which makes exfoliated structures difficult to achieve when epoxy molecules are penetrated into interlayer areas of clay platelets. Moreover, the mobility of epoxy molecules into clay galleries, as well as the inter- and extra-gallery reaction of epoxy should also be taken into consideration. According to Akbari and Bagheri [56], alkylammonium modified clay chains are able to occupy the gaps in interlayer areas, which decreases the diffusion of epoxy molecules, thus resulting in a limited increase of $d$-spacing values. On the other hand, hydrophilic properties of pristine MMT clays (i.e. Cloisite $\mathrm{Na}^{+}$) may have contributed to a relatively small increase in $d$-spacing value up to only $1.4 \mathrm{~nm}$ for nanocomposites. Conversely, organoclays modified by organophilic and alkylammonium cations tend to possess essentially hydrophobic clay surfaces with expanded interlayer areas, which can facilitate the diffusion of epoxy molecules [6, 24, 57]. 


\subsection{TEM morphological characterisation}

As a supplementary technique to XRD analysis for the investigation of clay dispersion, TEM was carried out on epoxy/Cloisite 93A nanocomposites with various clay contents, as illustrated in Fig. 4. It is evident from these TEM micrographs that combining three different pre-mixing processes tend to produce non-uniform clay dispersion, as evidenced by the presence of clay aggregates with skewed nanoclay layers. The addition of $3 \mathrm{wt} \%$ clays resulted in a mix of morphological structures, comprising agglomerated and partially intercalated/exfoliated clay structures (Fig. 4(a)). Increasing the clay content demonstrated a high tendency for the provision of intercalated structures rather than exfoliated structures as depicted in high magnification TEM results, Figs. 4(b), (d), (f) and (h). It clearly shows the presence of intercalated structures with an interlayer spacing shifted from $2.55 \mathrm{~nm}$ to approximately $3.6 \mathrm{~nm}$, Table 2. Moreover, exfoliated clay structures with single clay platelets can only be evidently seen in Figs. 4(b), (d) and (f). On the other hand, increasing the clay content from 3 to $10 \mathrm{wt} \%$ caused silicate layers to be clumped together, as indicated by the presence of clay aggregates with typical sizes ranging from 1 to $3 \mu \mathrm{m}$.

The above-mentioned fact implies that the combination of three different premixing with those processing parameters could not produce desirable epoxy/clay nanocomposites with better clay wettability. The processing parameters of mechanical mixing and ultrasonication selected in this study may lack the effective manufacturing of nanocomposites to break up clay aggregates and disperse fine clay particles uniformly in epoxy matrices. The other plausible reason for clay agglomeration can be attributed to applied centrifugal forces in the third stage of pre-mixing process, which allows the silicate layers of clay particles to stick together, thus leading to the reduced functionality of clays as effective nanofillers. Such a phenomenon is in good 
accordance with previous results obtained from Saber-Samandari et al. [50] by investigating the effect of centrifugal mixing at high rotor speeds on clay agglomeration. Consequently, optimum processing condition at different clay types and contents, as well as compatibility of physical and chemical properties of used coupling agents are the key to successfully manufacturing epoxy/clay nanocomposites with better clay wettability and excellent mechanical properties.

\subsection{SEM analysis}

The fracture surfaces of neat epoxy and epoxy/clay nanocomposites investigated by SEM are presented in SEM micrographs in Fig. 5 and Fig. 6. Neat epoxy samples exhibits typical smooth surfaces after brittle fracture with so-called "stream" marks adjacent to initial cracks (Fig. 5(a)). On the other hand, epoxy/clay nanocomposites possess significantly different morphology compared to those of neat epoxy with a clear sign of rougher fracture surfaces (Figs. 5(b)-(i)). Moreover, it can also be seen that increasing the clay content in nanocomposites further promotes the surface roughness level, signifying more brittle feature with embedded rigid clays.

On the other hand, the presence of clay aggregates with the size of approximately 2 to $5 \mu \mathrm{m}$, as seen in Figs. 5(b)-(i), indicates the pull-out of clay particles in fracture mechanism owing to the weak interfacial bonding between clay aggregates and epoxy matrices. Such observation is believed to further deteriorate mechanical properties of epoxy/clay nanocomposites. Moreover, increasing the clay content to $10 \mathrm{wt} \%$ induces serious clay clumps and agglomeration according to previous TEM results in Fig. 4. In general, nanofiller content above 5 wt\% may offer less success in producing highly dispersed nanofillers within nanocomposite systems. The other possible reason for clay agglomeration can be due to inappropriate selection of processing parameters to produce sufficient dissipation energy for particle separation. In order to achieve good 
clay wettability, it is essential to use high shear forces to overcome Van der Waals interactions among clay layers so that epoxy molecules can be easily diffused into clay interlayer areas and achieve the expansion of interlayer spacing, further resulting in well dispersed clay fillers within polymer matrices [38].

On the other hand, Figs. 6(a)-(h) demonstrate a large number of microvoids and microcracks for epoxy nanocomposites reinforced with organomodified and pristine clay types, namely Cloisite 10A, Cloisite 15 , Cloisite $93 \mathrm{~A}$ and Cloisite $\mathrm{Na}^{+}$. The crack propagation was initiated close to microvoids and clay aggregates due to weak epoxy network junctions around void edges. Therefore, the existence of microvoids can be attributed to several effects that may have taken place in aforementioned three different pre-mixing processes. During the shear mixing process, foamy and viscous mixed materials can be produced, which are hard to reduce in subsequent ultrasonication and centrifugal processes. Inappropriate mixing with a fast rotor speed can yield air entrapment or foamy mixture, built-up heat and poor clay dispersion, as illustrated from SEM results in Figs. 5 and 6. Despite the positive effect of centrifugal technique on bubble reduction [50], it may also break down large bubbles into microsized bubbles [58] as confirmed in Fig. 6 in this study. The use of inappropriate rotor speed makes it less effective to separate fillers/particles and reduce air bubbles in epoxy/clay mixtures. When the combination of three different premixing processes, consisting of mechanical mixing, ultrasonication and centrifugal mixing, are directly employed in this study, it is manifested that clay wettability into polymer matrices fails to be substantially enhanced without the optimsation of material formulation and processing conditions according to obtained morphological structures in TEM and SEM results. 


\subsection{Mechanical properties}

\subsubsection{Flexural properties}

Flexural testing results for epoxy/clay nanocomposites with different clay types and contents are demonstrated in Fig. 7. It is noted that epoxy/clay nanocomposites possess lower flexural strength than neat epoxy. Flexural strengths of epoxy nanocomposites reinforced with organomodified clays (i.e. Cloisite 10A, Cloisite 15 and Cloisite 93A) decreased with increasing the clay content. Quite differently, epoxy/ Cloisite $\mathrm{Na}^{+}$nanocomposites have an almost constant flexural strength at approximately $62 \mathrm{MPa}$ at the clay contents of 3-10 wt\% (Fig. 7(b)). Overall, epoxy/Cloisite 15 nanocomposites have achieved the maximum flexural strength with 3 wt\% clay inclusions, which, however, is still $12 \%$ lower than that of neat epoxy.

On the other hand, the addition of pristine and organomodified clays into epoxy matrices could enhance flexural moduli as well. Flexural moduli of nanocomposites with the addition of 3 wt\% Cloisite 15 and Cloisite $\mathrm{Na}^{+}$were significantly improved by 21 and 17\%, respectively, as opposed to that of neat epoxy, Fig. 7(a). Nevertheless, further increase in the clay content up to $10 \mathrm{wt} \%$ induces the retention of flexural moduli for epoxy/ Cloisite $\mathrm{Na}^{+}$nanocomposites at approximately $3.2 \mathrm{GPa}$. Conversely, flexural moduli of epoxy/Cloisite 15 nanocomposites demonstrate a declining trend above the clay content of $3 \mathrm{wt} \%$. Meanwhile, epoxy nanocomposites reinforced with Cloisite 10A and Cloisite 93A have a moderate increase of flexural moduli up to $3 \mathrm{wt} \%$ clay inclusions, which is followed by a slight reduction from 3 to $8 \mathrm{wt} \%$ in the clay content when compared with that of neat epoxy. Thus, it can be inferred that the addition of $3 \mathrm{wt} \%$ clays is the optimum level of filler contents for both pristine and organomodified clays.

The reduction in flexural strength and flexural moduli for all nanocomposites can be associated with many factors in material processing and morphology including clay 
agglomeration and poor clay wettability [28], as well as weak interfacial bonding between clay particles and epoxy matrices. In particular, a high level of clay agglomeration can hinder epoxy network junction, which adversely influences the rigidity of nanocomposites. Low clay dispersibility and poor interfacial interaction inevitably lead to the less enhancement of flexural moduli and diminished flexural strengths for epoxy/clay nanocomposites. Furthermore, the presence of microvoids detected from TEM and SEM results also means typical defects to initiate the crack propagation around void edges, further worsening flexural properties of epoxy/clay nanocomposites.

\subsubsection{Impact properties}

The effect of clay type and content on impact strengths of epoxy nanocomposites is presented in Fig. 8. The impact strength of nanocomposites reinforced with 3 wt\% Cloisite $\mathrm{Na}^{+}$is approximately $24 \%$ higher (as highest strength level) than that of neat epoxy when compared to $12 \%$ and $14 \%$ increases in corresponding epoxy/Cloisite 10A nanocomposites and epoxy/Cloisite 93A nanocomposites, respectively. Afterwards, the mild decrease of impact strengths of all nanocomposites is revealed with increasing the clay content beyond 3 wt\% except epoxy/Cloisite 10A nanocomposites with a significant decreasing trend up to $10 \mathrm{wt} \%$. Overall, epoxy/Cloisite 15 nanocomposites possess the least decreasing level of impact strengths in range from 3 to $10 \mathrm{wt} \%$ in clay contents.

The improvement of impact strengths of nanocomposites, especially at a low clay content of $3 \mathrm{wt} \%$, benefit from relatively good clay dispersion with exfoliated/intercalated structures to hinder the cracks. More well dispersed rigid clay platelets, to a certain extent, constrain the internal deformation (i.e. straining effect) of epoxy matrices prone to crack initiation, resulting in higher reinforcement efficiency. 
On the other hand, the presence of clay aggregates and microvoids acting as stress concentration sites for the crack growth eventually causes earlier impact failure of epoxy/clay nanocmposites mainly at high clay contents.

\subsubsection{Rockwell hardness}

The influence of clay type and content on Rockwell hardness of epoxy/clay nanocomposites is depicted in Fig. 9. Evidently, a consistently modest decrease in hardness values of nanocomposites is manifested with increasing the clay content irrespective of clay types when compared to that of near epoxy. When varying the clay content from 3 to $10 \%$, hardness values of nanocomposites are reduced from approximately 76 to $72 \mathrm{HRE}$ (decreasing level of 4\%). The maximum hardness appears to be achieved at about 76 HRE for epoxy nanocomposites reinforced with 3 wt\% Cloisite 15, which is still slightly below that of neat epoxy. Exceptionally, epoxy/Cloisite $\mathrm{Na}^{+}$nanocomposites undergo initial hardness retention when the clay content increases with comparable hardness values to that of neat epoxy. The decreasing trend of hardness for epoxy/clay nanocomposites may be ascribed to poor clay wettability leading to agglomerated structures rather than high levels of exfoliated/intercalated counterparts, as well as the coexistence of microvoids and pores [58].

\subsection{DSC thermal analysis}

The DSC thermograms and $T_{g}$ values for epoxy/clay nanocomposites under investigation are depicted in Fig. 10 and 11, respectively. Overall, $T_{g}$ values of epoxy/clay nanocomposites were found to be higher than that of neat epoxy, which suggests that rigid clay particles can restrict the mobility of epoxy molecules so that a higher $T_{g}$ is generally required to overcome the phase change of epoxy/clay nanocomposites. The addition of $3 \mathrm{wt} \%$ clay for epoxy nanocomposites reinforced 
with Cloisite 10A, Cloisite $\mathrm{Na}^{+}$, Cloisite $93 \mathrm{~A}$ and Cloisite 15 was found to consistently increase $T_{g}$ by approximately 11, 13, 16 and 23\%, respectively. Even though $T_{\mathrm{g}}$ decreases slightly at the clay content from 3 to $5 \mathrm{wt} \%$ for epoxy nanocomposites reinforced with Cloisite $\mathrm{Na}^{+}$, Cloisite 93A and Cloisite 15, associated values were still higher than that of neat epoxy. More remarkably, epoxy/Cloisite 15 nanocomposites exhibit a maximum increase of $28 \%$ in $T_{g}$ (relative to neat epoxy) with $10 \mathrm{wt} \%$ clay inclusions.

These results for the enhancement of $T_{g}$ can also be associated with interaction hindrance of epoxy network with embedded rigid clay particles into epoxy matrices, high clay dispersibility at the low content levels, degree of crosslinking, chain flexibility and molecular weight of used epoxy resin $[3,59]$. The slight decrease in $T_{g}$ at clay contents of 3-8 wt\% for Cloisite $\mathrm{Na}^{+}$, Cloisite 93A and Cloisite 15 inclusions and 5-8 wt\% for Cloisite 10A inclusions may arise from the reduction of the degree of crosslinking density in epoxy molecules.

\section{Conclusions}

This study has investigated the effect of material formulation of synthesised epoxy/clay nanocomposites on their resulting mechanical and thermal properties using three combined pre-mixing processes, namely shear mixing, ultrasonication and centrifugation. A mix of intercalated, exfoliated and predominantly agglomerated clay structures was observed by XRD, TEM and SEM. Based on the combination of three different pre-mixing processes, epoxy/clay nanocomposites possess decreased flexural strengths (up to 53\%) and smaller Rockwell hardness values (up to the decreasing level of 7\%) when compared to those of neat epoxy. These findings are due to weak interfacial bonding between clay fillers and epoxy matrices, as well as the presence of clay aggregates and microvoids acting as stress concentration sites and typical defects, respectively for crack initiation. Moreover, lower maximum 
flexural modulus and impact strength of nanocomposites are affected by poor clay wettability and clay agglomeration according to SEM and TEM results. Finally, $T_{\mathrm{g}}$ of nanocomposites increases regardless of clay type as compared with that of neat epoxy. The mobility of epoxy molecules is believed to be obstructed with the inclusion of rigid clays. Further optimisation of material formulation and processing condition is required to achieve more desirable clay dispersibility and excellent mechanical and thermal properties of epoxy/clay nanocomposites.

\section{Acknowledgements}

H. Salam gratefully acknowledges the Directorate General of Higher Education (DGHE), the Ministry of Education and Culture, Government of Republic Indonesia, for granting him a PhD scholarship (reference no. 4866/ E4.4/K/2013). The authors are thankful to Ms. Elaine Miller from the Electron Microscopy Laboratory and Mr. Ming Lim from the Material Testing Laboratory at Curtin University for assisting in SEM analysis and flexural tests, respectively. The authors are also indebted to Associate Prof. Martin Saunders and Dr. Aaron Dodd at the Centre for Microscopy, Characterisation and Analysis (CMCA), The University of Western Australia for their support with XRD and TEM analysis.

\section{References}

1. Qi B, Zhang QX, Bannister M, Mai YW (2006) Investigation of the mechanical properties of DGEBA-based epoxy resin with nanoclay additives. Compos Struct 75(1-4):514-519. DOI:10.1016/j.compstruct.2006.04.032

2. Zhang D, Zhou C-H, Lin C-X, Tong D-S, Yu W-H (2010) Synthesis of clay minerals. Appl Clay Sci 50(1):1-11. DOI:10.1016/j.clay.2010.06.019 
3. Alexandre M, Dubois P (2000) Polymer-layered silicate nanocomposites: preparation, properties and uses of a new class of materials. Mater Sci Eng: R: Reports 28(1-2):1-63. DOI:10.1016/S0927-796X(00)00012-7

4. Cho JW, Paul DR (2001) Nylon 6 nanocomposites by melt compounding. Polymer 42(3):1083-1094. DOI:10.1016/S0032-3861(00)00380-3

5. Yasmin A, Luo JJ, Abot JL, Daniel IM (2006) Mechanical and thermal behavior of clay/epoxy nanocomposites. Compos Sci Technol 66(14):2415-2422. DOI:10.1016/j.compscitech.2006.03.011

6. Chen KH, Yang SM (2002) Synthesis of epoxy-montmorillonite nanocomposite. J Appl Polym Sci 86(2):414-421. DOI:10.1002/app.10986

7. Shiravand F, Hutchinson JM, Calventus Y, Ferrando F (2014) Comparison of the nanostructure and mechanical performance of highly exfoliated epoxy-clay nanocomposites prepared by three different protocols. Materials 7(6):4196-4223. DOI:10.3390/ma7064196

8. Ianchis R, Rosca ID, Ghiurea M, Spataru CI, Nicolae CA, Gabor R, Raditoiu V, Preda S, Fierascu RC, Donescu D (2015) Synthesis and properties of new epoxyorganolayered silicate nanocomposites. Appl Clay Sci 103(0):28-33. DOI:10.1016/j.clay.2014.10.020

9. Wang M, Fan X, Thitsartarn W, He C (2015) Rheological and mechanical properties of epoxy/clay nanocomposites with enhanced tensile and fracture toughnesses. Polymer 58:43-52. DOI:10.1016/j.polymer.2014.12.042

10. Hussain F, Hojjati M, Okamoto M, Gorga R E (2006) Polymer-matrix nanocomposites, processing, manufacturing, and application: An overview. J Compos Mater 40(17):1511-1575. DOI: 10.1177/0021998306067321 
11. Albdiry MT, Yousif BF, Ku H, Lau KT (2013) A critical review on the manufacturing processes in relation to the properties of nanoclay/polymer composites. J Compos Mater 47(9):1093-1115. DOI:10.1177/0021998312445592

12. H. Salam, Dong Y, Davies IJ (2015) Development of bio-based polymer/clay nanocomposites: A critical review. In: Y. Dong, R. Umer, Lau AK-T (eds) Fillers and Reinforcements for Advanced Nanocomposites. Woodhead Publishing (In Imprint of Elsevier), UK, pp 101-132. DOI:10.1016/B978-0-08-100079-3.000065

13. Lan T, Pinnavaia TJ (1994) Clay-reinforced epoxy nanocomposites. Chem Mat 6(12):2216-2219. DOI: 10.1021/cm00048a006

14. Ha SR, Ryu SH, Park SJ, Rhee KY (2007) Effect of clay surface modification and concentration on the tensile performance of clay/epoxy nanocomposites. Mater Sci Eng A 448(1-2):264-268. DOI:10.1016/j.msea.2006.10.052

15. Wang H, Hoa SV, Wood-Adams PM (2006) New method for the synthesis of clay/epoxy nanocomposites. J Appl Polym Sci 100(6):4286-4296. DOI:10.1002/app.23859

16. Sundaram S, Nagalingam R, Satheesh Raja R (2008) Experimental analysis on tensile properties of FRP with nano clay. Inter J Adv Manuf Technol 1-5. DOI: $10.1007 / \mathrm{s} 00170-008-1868-8$

17. Kornmann X, Thomann R, Mülhaupt R, Finter J, Berglund L (2002) Synthesis of amine-cured, epoxy-layered silicate nanocomposites: The influence of the silicate surface modification on the properties. J Appl Polym Sci 86(10):2643-2652. DOI:10.1002/app.11279 
18. Wu L, Hoa SV, Minh T, Ton T (2006) Effects of composition of hardener on the curing and aging for an epoxy resin system. J Appl Polym Sci 99(2):580-588. DOI:10.1002/app.22493

19. Devasenapathi V, Monish P, Balasivanandha Prabu S (2009) Experimental investigation of tensile creep behavior of polymer nanocomposites. Inter J Adv Manuf Technol 44(3):412-418. DOI: 10.1007/s00170-008-1877-7

20. Dong Y, Bhattacharyya D (2008) Effects of clay type, clay/compatibiliser content and matrix viscosity on the mechanical properties of polypropylene/organoclay nanocomposites. Compos Part A: Appl Sci Manuf 39(7):1177-1191. DOI:10.1016/j.compositesa.2008.03.006

21. Umer R, Li Y, Dong Y, Haroosh H J, Liao K (2015) The effect of graphene oxide (GO) nanoparticles on the processing of epoxy/glass fiber composites using resin infusion. Inter J Adv Manuf Technol 81(9):2183-2192. DOI: 10.1007/s00170$015-7427-1$

22. Xu Y, Hoa S V (2008) Mechanical properties of carbon fiber reinforced epoxy/clay nanocomposites. Compos Sci Technol 68(3-4):854-861. DOI:10.1016/j.compscitech.2007.08.013

23. Jo B-W, Park S-K, Kim D-K (2008) Mechanical properties of nano-MMT reinforced polymer composite and polymer concrete. Constr Build Mater 22(1):14-20. DOI:10.1016/j.conbuildmat.2007.02.009

24. Triantafillidis CS, LeBaron PC, Pinnavaia TJ (2002) Thermoset epoxy-clay nanocomposites: The dual role of $\alpha, \omega$-diamines as clay surface modifiers and polymer curing agents. J Solid State Chem 167(2):354-362. DOI:10.1006/jssc.2001.9541 
25. Nah C, Ryu HJ, Kim WD, Choi S-S (2002) Barrier property of clay/Acrylonitrile-butadiene copolymer nanocomposite. Polym Adv Technol 13(9):649-652. DOI:10.1002/pat.325

26. Brown JM, Curliss D, Vaia RA (2000) Thermoset-layered silicate nanocomposites. Quaternary ammonium montmorillonite with primary diamine cured epoxies. Chem Mater 12(11):3376-3384. DOI:10.1021/cm000477

27. Azeez AA, Rhee KY, Park SJ, Hui D (2013) Epoxy clay nanocomposites processing, properties and applications: A review. Compos Part B: Eng 45(1):308-320. DOI:10.1016/j.compositesb.2012.04.012

28. Bindu Sharmila TK, Ayswarya EP, Abraham BT, Sabura Begum PM, Thachil ET (2014) Fabrication of partially exfoliated and disordered intercalated cloisite epoxy nanocomposites via in situ polymerization: Mechanical, dynamic mechanical, thermal and barrier properties. Appl Clay Sci 102(0):220-230. DOI: 10.1016/j.clay.2014.09.043

29. Chin I-J, Thurn-Albrecht T, Kim H-C, Russell TP, Wang J (2001) On exfoliation of montmorillonite in epoxy. Polymer 42(13):5947-5952. DOI:10.1016/S00323861(00)00898-3

30. Pascual-Sánchez V, Martín-Martínez JM (2006) Influence of the curing temperature in the mechanical and thermal properties of nanosilica filled epoxy resin coating. Macromol Symp 233(1):137-146. DOI:10.1002/masy.200690010

31. Lee A, Lichtenhan J D (1999) Thermal and viscoelastic property of epoxy-clay and hybrid inorganic-organic epoxy nanocomposites. J Appl Polym Sci 73(10):1993-2001. DOI: 10.1002/(SICI)1097-4628(19990906)73:10<1993::AIDAPP18>3.0.CO;2-Q 
32. Kornmann X, Lindberg H, Berglund LA (2001) Synthesis of epoxy-clay nanocomposites: influence of the nature of the clay on structure. Polymer 42(4):1303-1310. DOI:10.1016/s0032-3861(00)00346-3

33. Kong D, Park CE (2003) Real time exfoliation behavior of clay layers in epoxy-clay nanocomposites. Chem Mater 15(2):419-424. DOI:10.1021/cm0205837

34. Wang Q, Song C, Lin W (2003) Study of the exfoliation process of epoxy-clay nanocomposites by different curing agents. J Appl Polym Sci 90(2):511-517. DOI:10.1002/app.12689

35. Xie F, Pollet E, Halley PJ, Avérous L (2013) Starch-based nano-biocomposites. Prog Polym Sci 38(10-11):1590-1628. DOI:10.1016/j.progpolymsci.2013.05.002

36. LeBaron PC, Wang Z, Pinnavaia TJ (1999) Polymer-layered silicate nanocomposites: an overview. Appl Clay Sci 15(1-2):11-29. DOI: 10.1016/S0169-1317(99)00017-4

37. Chen C, Tolle TB (2004) Fully exfoliated layered silicate epoxy nanocomposites. J Polym Sci Part B: Polym Phys 42(21):3981-3986. DOI:10.1002/polb.20259

38. Gupta N, Lin T, Shapiro M (2007) Clay-epoxy nanocomposites: Processing and properties. JOM 59(3):61-65. DOI:10.1007/s11837-007-0041-4

39. Atiemo-Obeng VA, Penney W, Armenante PM (2004) Solid-liquid mixing. In: Handbook of industrial mixing: Science and Practice, 1st ed. Wiley, Hoboken. 543-584. DOI:10.1002/0471451452.ch10

40. Usuki A, Kojima Y, Kawasumi M, Okada A, Fukushima Y, Kurauchi T, Kamigaito O (1993) Synthesis of nylon 6-clay hybrid. J Mater Res 8(05):11791184. DOI:10.1557/JMR.1993.1179 
41. Park JY, Davis TB, Sullivan PL (2010) Parametric study on the fabrication of clay-containing thermosetting nanocomposites. J Reinf Plastics Compos 29(5):755-770. DOI:10.1177/0731684408100698

42. Yasmin A, Abot JL, Daniel IM (2003) Processing of clay/epoxy nanocomposites by shear mixing. Scripta Mater 49(1):81-86. DOI:10.1016/S13596462(03)00173-8

43. Giancarlo C, Pedro C (2011) Introduction to Sonochemistry. In: Mudhoo A (ed) Handbook on Applications of Ultrasound. CRC Press. DOI: 10.1201/b11012-3

44. Suslick KS (1990) Sonochemistry. Science 247 (4949):1439-1445.

45. Kaboorani A, Riedl B, Blanchet P (2013) Ultrasonication technique: A method for dispersing nanoclay in wood adhesives. J Nanomater 2013:9. DOI:10.1155/2013/341897

46. Lam C-k, Lau K-t, Cheung H-y, Ling H-y (2005) Effect of ultrasound sonication in nanoclay clusters of nanoclay/epoxy composites. Mater Lett 59(11):13691372. DOI:10.1016/j.matlet.2004.12.048

47. Bittmann B, Haupert F, Schlarb AK (2009) Ultrasonic dispersion of inorganic nanoparticles in epoxy resin. Ultrason Sonochem 16(5):622-628. DOI:10.1016/j.ultsonch.2009.01.006

48. Bittmann B, Haupert F, Schlarb AK (2011) Preparation of $\mathrm{TiO}_{2}$ /epoxy nanocomposites by ultrasonic dispersion and their structure property relationship. Ultrason Sonochem 18(1):120-126. DOI:10.1016/j.ultsonch.2010.03.011

49. Dean K, Krstina J, Tian W, Varley RJ (2007) Effect of ultrasonic dispersion methods on thermal and mechanical properties of organoclay epoxy nanocomposites. Macromol Mater Eng $292 \quad$ (4):415-427. DOI:10.1002/mame.200600435 
50. Saber-Samandari S, Khatibi AA, Basic D (2007) An experimental study on clay/epoxy nanocomposites produced in a centrifuge. Compos Part B: Eng 38(1):102-107. DOI:10.1016/j.compositesb.2006.03.010

51. Kabakov D, Tate JS, Koo JH (2011) Effect of dispersion techniques on thermal and mechanical properties of phenolic/E-glass nanocomposites. J Fire Sci 29(5):387-402. DOI: 10.1177/0734904110396160

52. Agubra V, Owuor P, Hosur M (2013) Influence of nanoclay dispersion methods on the mechanical behavior of E-glass/epoxy nanocomposites. Nanomaterials 3(3):550. DOI: 10.3390/nano3030550

53. Ford TC, Graham JM (1991) An Introduction to centrifugation. BIOS Scientific Pub, Oxford, UK, p1-20.

54. Bordes P, Pollet E, Avérous L (2009) Nano-biocomposites: Biodegradable polyester/nanoclay systems. Prog Polym Sci 34(2):125-155.

DOI:10.1016/j.progpolymsci.2008.10.002

55. Becker O, Cheng Y-B, Varley RJ, Simon GP (2003) Layered silicate nanocomposites based on various high-functionality epoxy resins: The influence of cure temperature on morphology, mechanical properties and free volume. Macromolecules 36(5):1616-1625. DOI:10.1021/ma0213448

56. Akbari B, Bagheri R (2007) Deformation mechanism of epoxy/clay nanocomposite. Eur Polym J 43(3):782-788.

DOI:10.1016/j.eurpolymj.2006.11.028

57. Tjong SC (2006) Structural and mechanical properties of polymer nanocomposites. Mater Sci Eng: R: Reports 53(3-4):73-197. DOI:10.1016/j.mser.2006.06.001 
58. Zhang H, Popp M, Hartwig A, Madler (2012) Synthesis of polymer/inorganic nanocomposite films using highly porous inorganic scaffolds. Nanoscale 4(7):2326-2332. DOI:10.1039/C2NR12029A

59. Krishnamachari P, Zhang J, Lou J, Yan J, Uitenham L (2009) Biodegradable poly(lactic acid)/clay nanocomposites by melt intercalation: A study of morphological, thermal and mechanical properties. Inter J Polym Anal Charact 14(4):336-350. DOI:10.1080/10236660902871843 


\section{List of Figures}

Fig. 1 Illustrative mechanisms of three different pre-mixing processes: (a) mechanical mixing, (b) ultrasonication and (c) centrifugation.

Fig. 2 Flow chat of combined pre-mixing processes for manufacturing epoxy/clay nanocomposites.

Fig. 3 XRD patterns of epoxy/clay nanocomposites based on different clay types and contents: (a) Cloisite $\mathrm{Na}^{+}$, (b) Cloisite 10A, (c) Cloisite 15 and (d) Cloisite 93A.

Fig. 4 TEM micrographs of epoxy/Cloisite 93A nanocomposites with different clay contents and magnification levels: (a) 3 wt\% (1200×), (b) 3 wt\% (80000×), (c) $5 \mathrm{wt} \%(1200 \times),(d) 5 \mathrm{wt} \%(80000 \times),(\mathrm{e}) 8 \mathrm{wt} \%(1200 \times)$, (f) $8 \mathrm{wt} \%$ (80000×), (g) 10wt\% (1200×) and (d) $10 \mathrm{wt} \%(80000 \times)$. The letters A, I and E represent agglomerated, intercalated and exfoliated clay structures, respectively.

Fig. 5 SEM micrographs of epoxy/clay nanocomposites with different clay types and contents: (a) neat epoxy, (b) 3 wt\% Cloisite 10A, (c) $10 \mathrm{wt} \%$ Cloisite 10A, (d) 3 wt $\%$ Cloisite 15, (e) 10wt\% Cloisite 15, (f) 3 wt $\%$ Cloisite 93A, (g) $10 \mathrm{wt} \%$ Cloisite 93A, (h) $3 \mathrm{wt} \%$ Cloisite $\mathrm{Na}^{+}$and (i) $10 \mathrm{wt} \%$ Cloisite $\mathrm{Na}^{+}$. The letters CA and MV in circled areas represent clay aggregates, microvoids, respectively.

Fig. 6 SEM micrograph of epoxy/clay nanocomposites with different clay types and contents at high magnification levels. (a) 3 wt\% Cloisite 10A, (b) $10 \mathrm{wt} \%$ Cloisite 10A, (c) $3 \mathrm{wt} \%$ Cloisite 15, (d) 10wt\% Cloisite 15, (e) $3 \mathrm{wt} \%$ Cloisite 93A, (f) 10 wt\% Cloisite 93A, (g) 3 wt\% Cloisite $\mathrm{Na}^{+}$and (h) 10 
wt\% Cloisite $\mathrm{Na}^{+}$. The letters CA, MV and MC in circled areas represent clay aggregates, microvoids and microcracks, respectively.

Fig. 7 Flexural properties of epoxy/clay nanocomposites with different clay types and contents: (a) flexural modulus and (b) flexural strength.

Fig. 8 Impact strength of epoxy/clay nanocomposites with different clay types and contents.

Fig. 9 Rockwell hardness of epoxy/clay nanocomposites with different clay types and contents.

Fig. 10 DSC thermograms of epoxy nanocomposites reinforced with (a) Cloisite $\mathrm{Na}^{+}$, (b) Cloisite 10A, (c) Cloisite 15 and (d) Cloisite 93A.

Fig. $11 T_{\mathrm{g}}$ of epoxy/clay nanocomposites with different clay types and contents. 

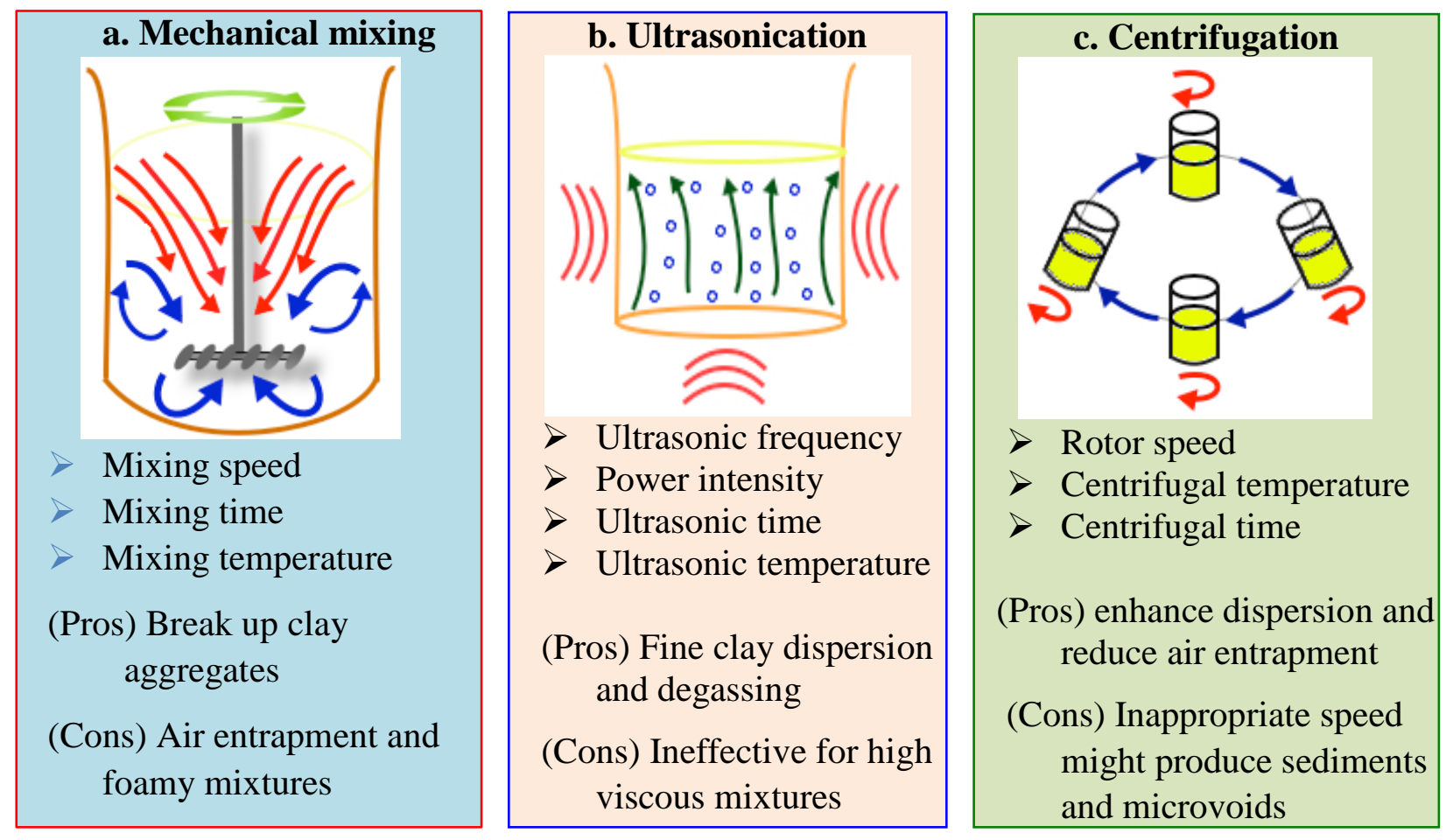

Fig. 1 


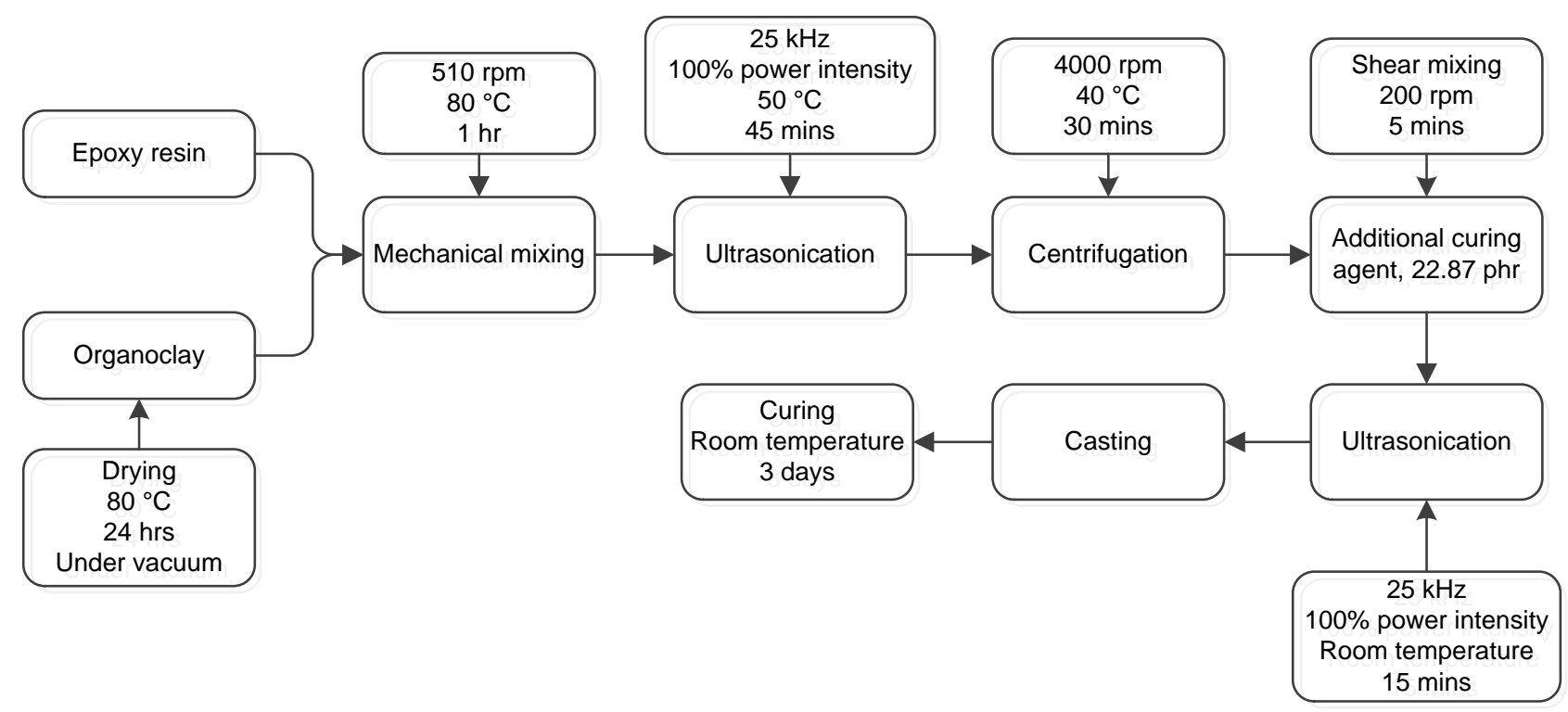

Fig. 2 
(a)

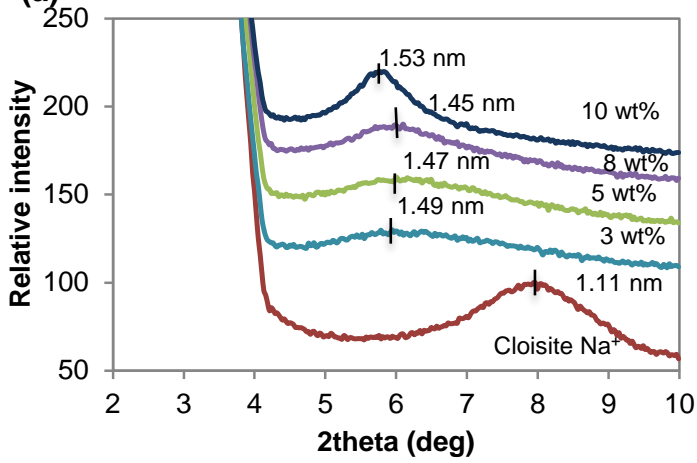

(c)

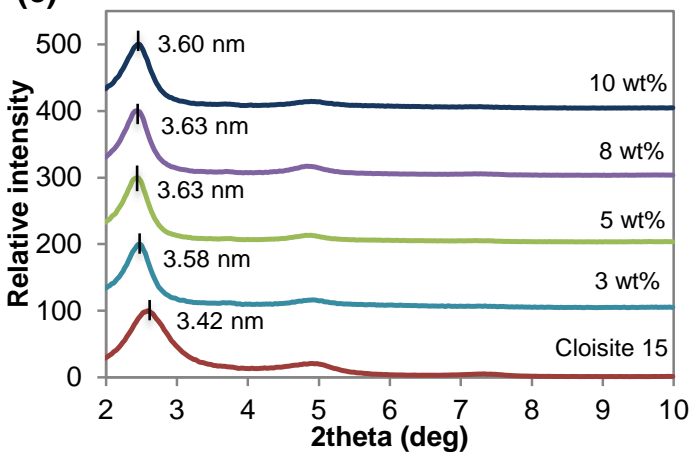

(b)

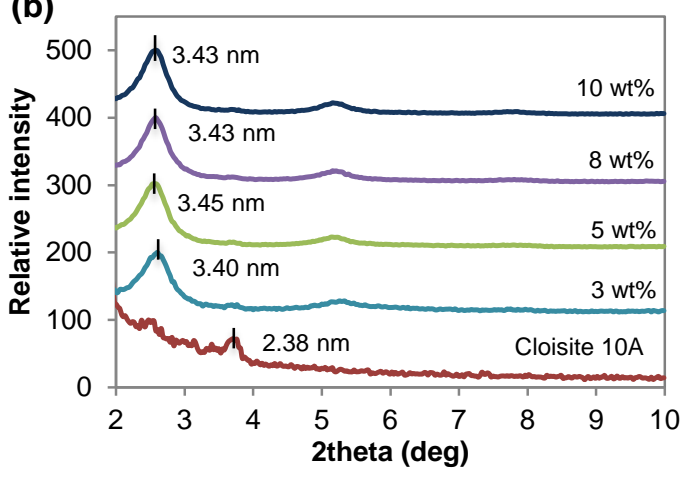

(d)

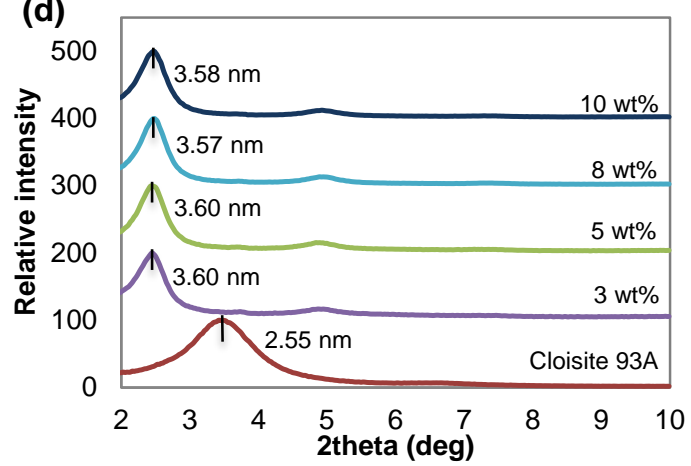

Fig. 3 

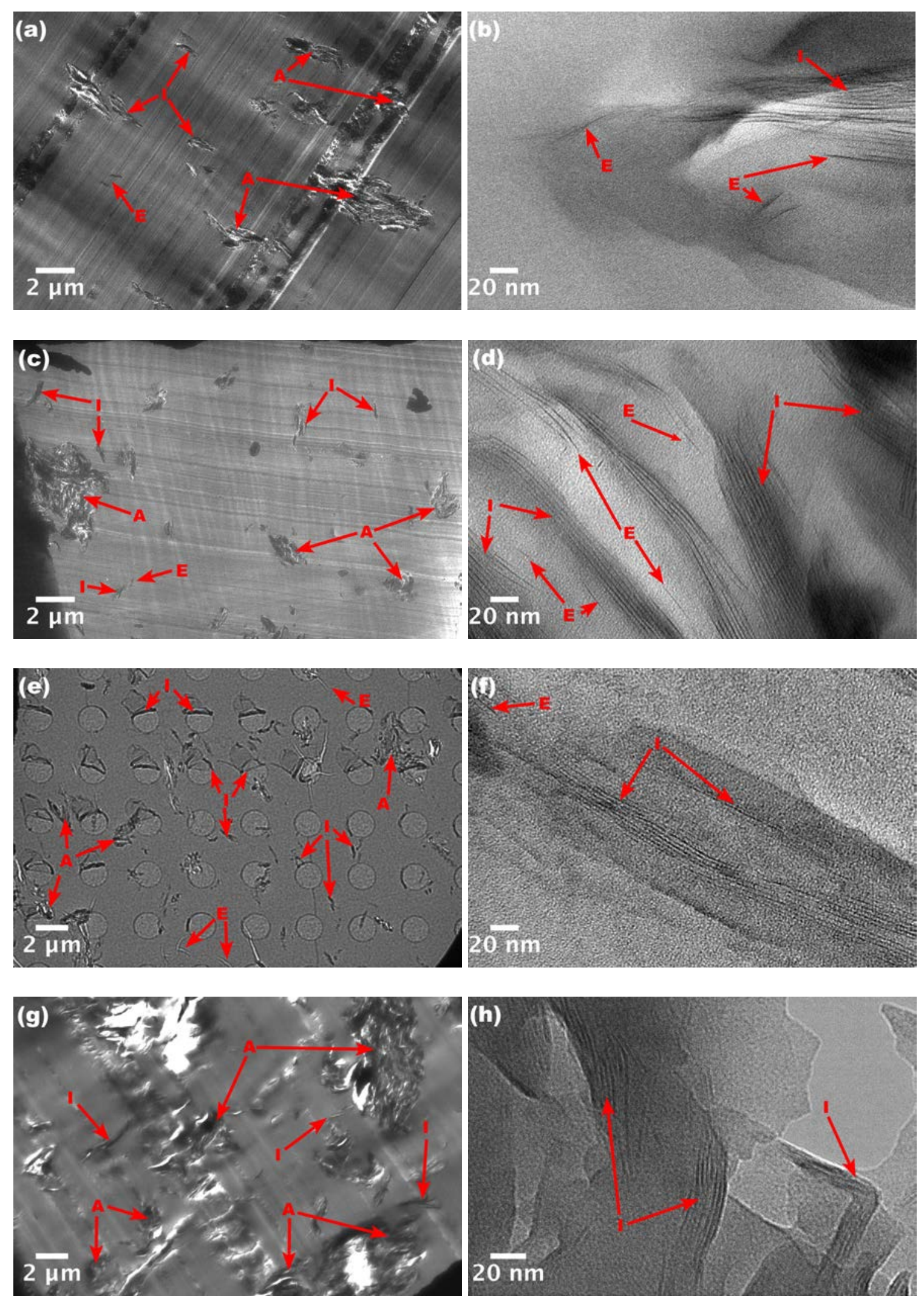

Fig. 4 


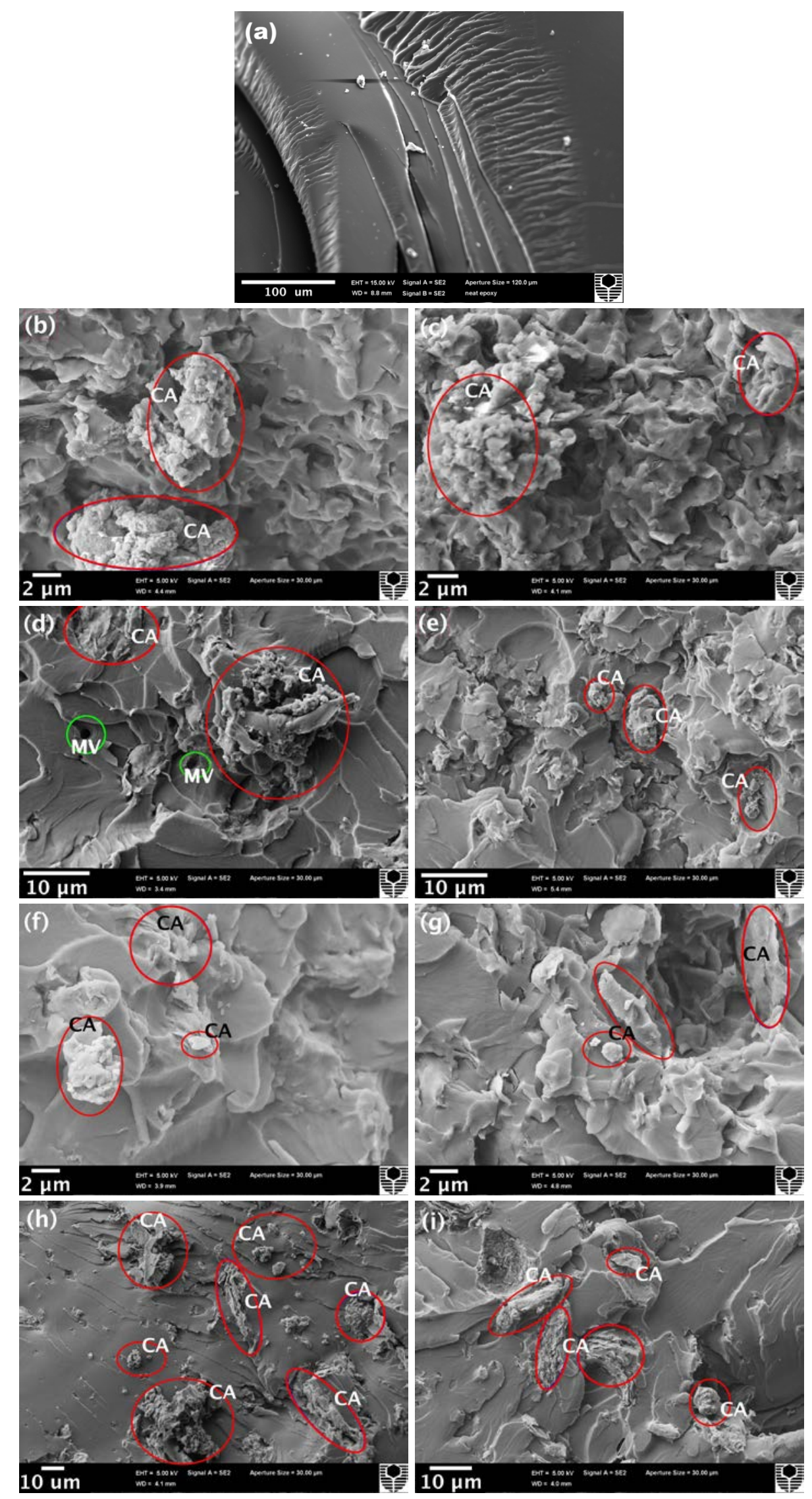

Fig. 5 

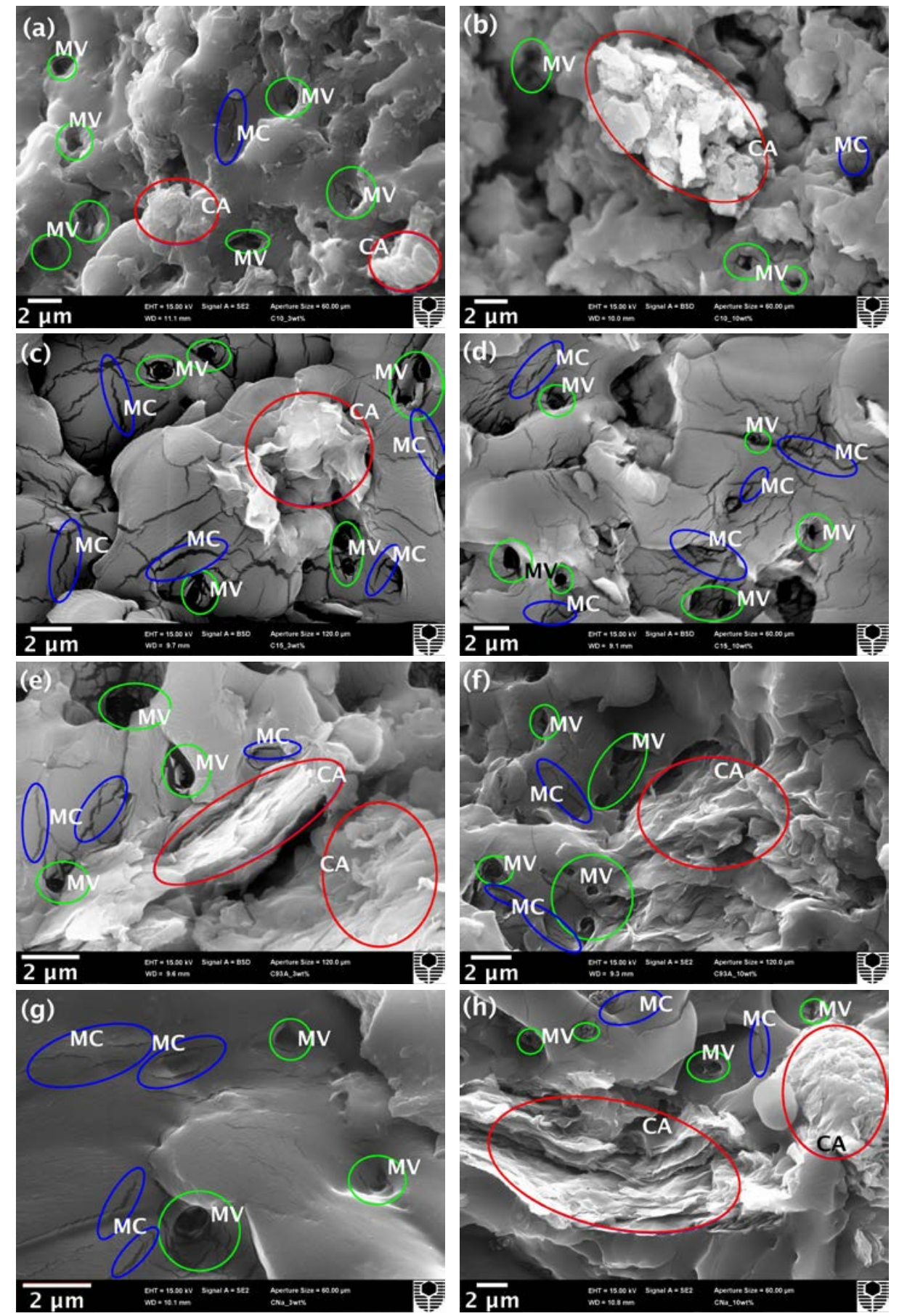

Fig. 6 

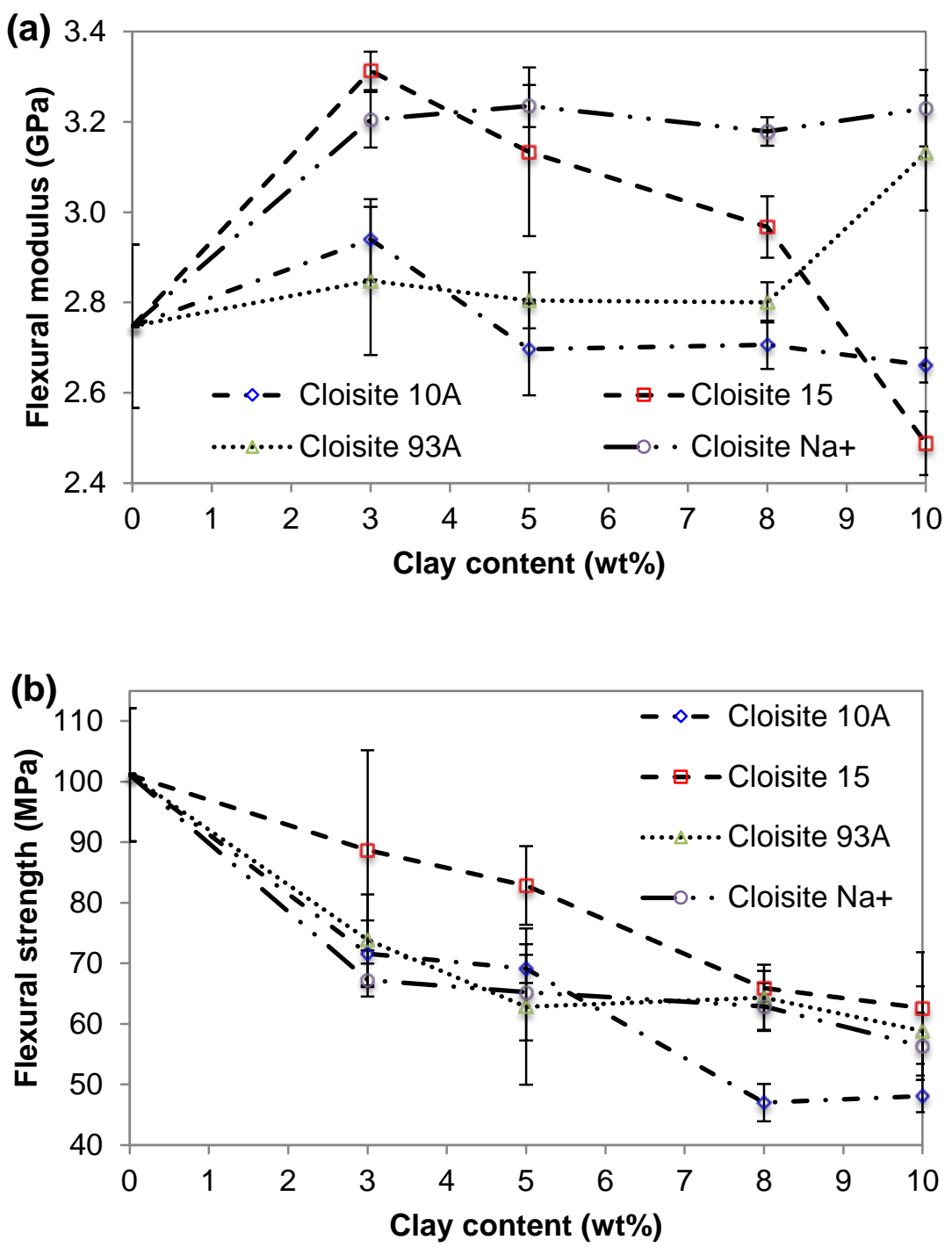

Fig. 7 


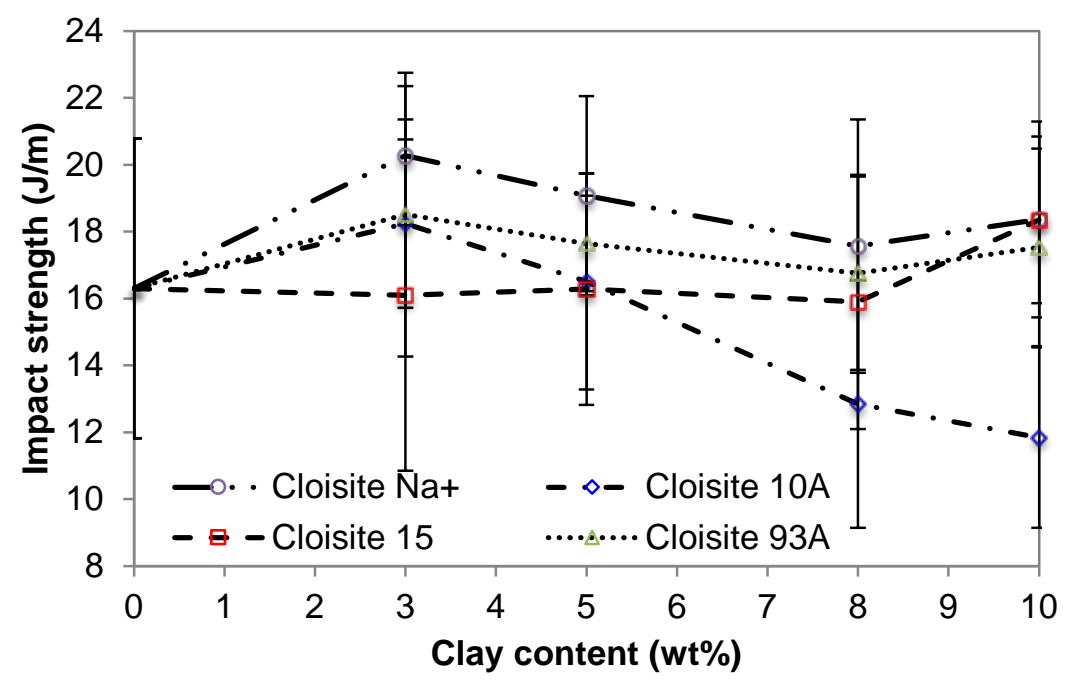

Fig. 8 


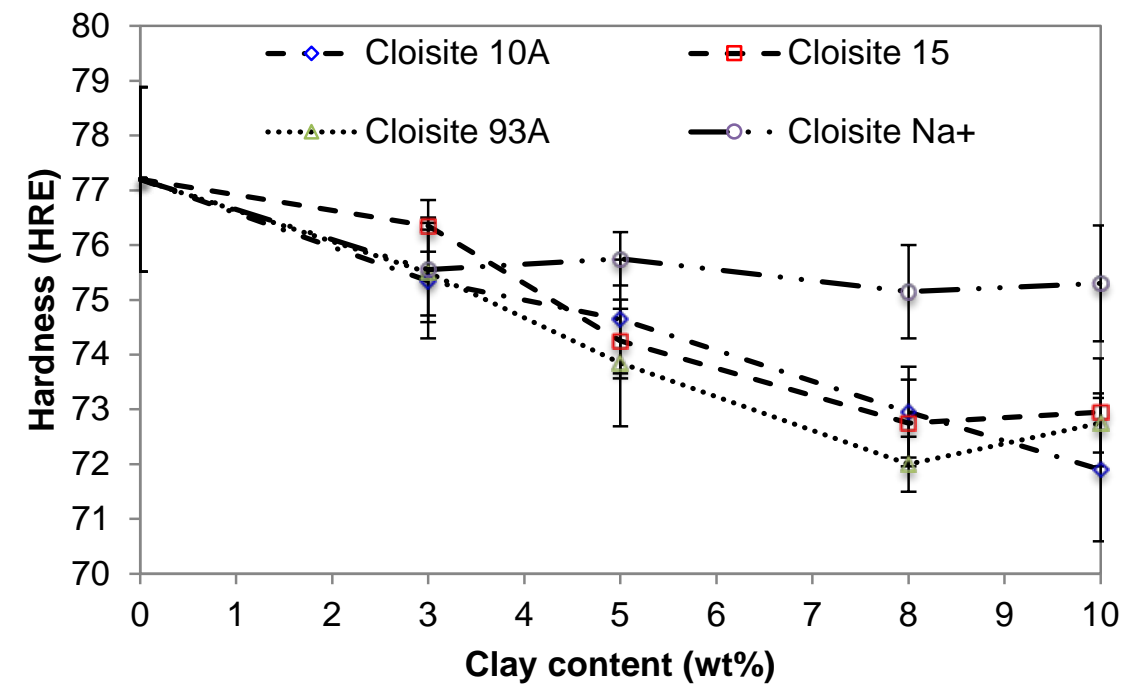

Fig. 9 

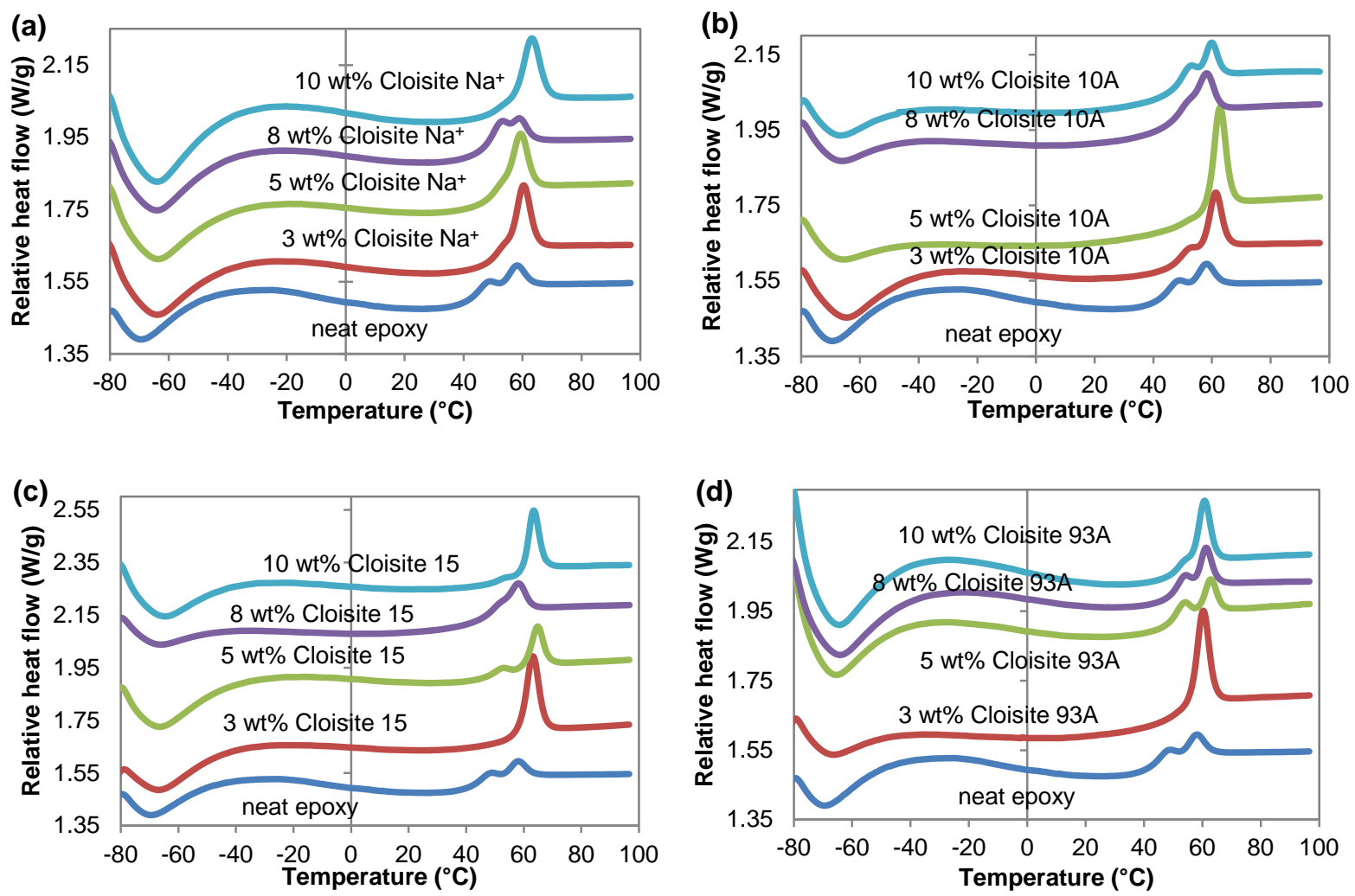

Fig. 10 


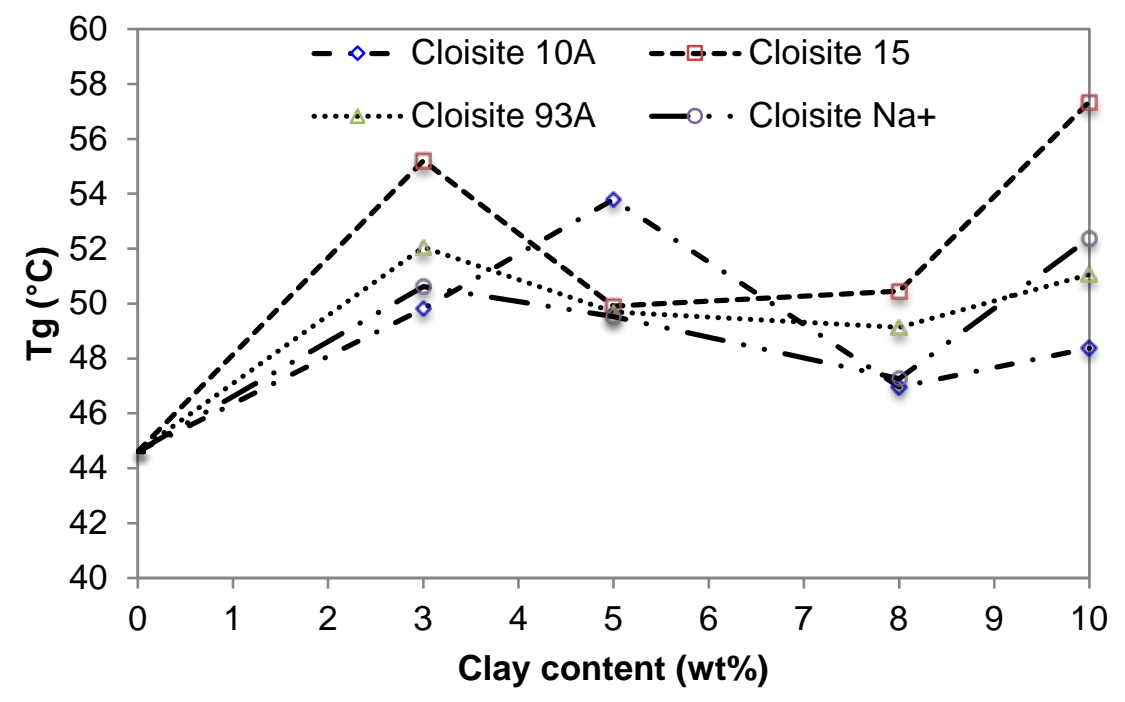

Fig. 11 
Table 1. Specifications of Cloisite ${ }^{\circledR}$ clays $[12,54]$

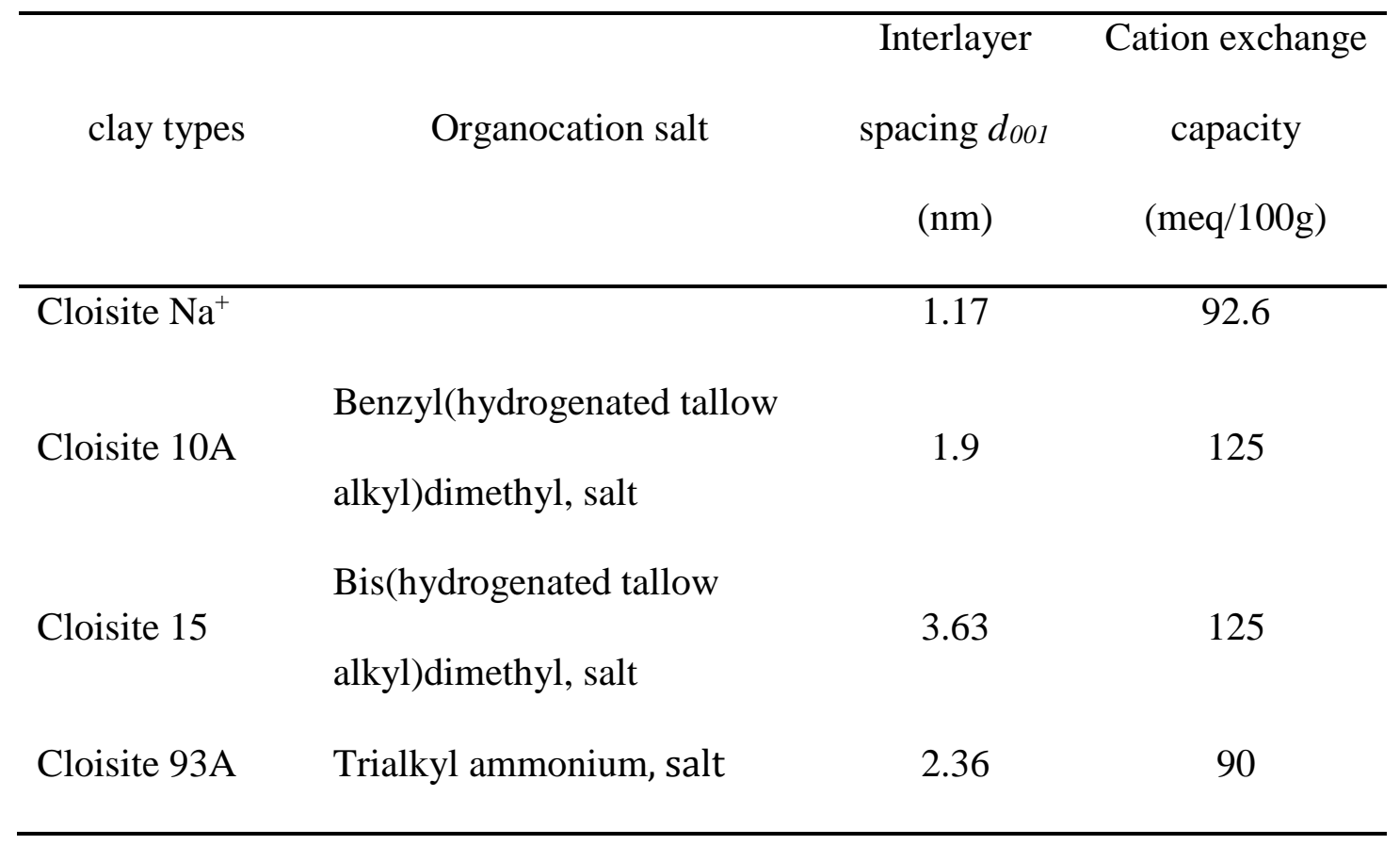


Table 2. Summary of interlayer spacing values for as-received clays and epoxy/clay nanocomposites

\begin{tabular}{|c|c|c|c|c|}
\hline \multirow[b]{2}{*}{ No } & \multirow[b]{2}{*}{ Material sample } & \multicolumn{3}{|c|}{ XRD Peak } \\
\hline & & $2 \theta$ & $\begin{array}{c}\text { Interlayer spacing } \\
d_{001}(\mathrm{~nm})\end{array}$ & $\%$ increase of $d_{001}$ \\
\hline 1 & Cloisite $\mathrm{Na}^{+}\left(\mathrm{CNa}^{+}\right)$ & 7.94 & 1.11 & \\
\hline 2 & $\mathrm{CNa}^{+}-3 \mathrm{wt} \%$ & 5.94 & 1.49 & 33.54 \\
\hline 3 & $\mathrm{CNa}^{+}-5 \mathrm{wt} \%$ & 5.99 & 1.47 & 32.37 \\
\hline 4 & $\mathrm{CNa}^{+}-8 \mathrm{wt} \%$ & 6.10 & 1.45 & 30.09 \\
\hline 5 & $\mathrm{CNa}^{+}-10 w t \%$ & 5.76 & 1.53 & 37.80 \\
\hline 6 & Cloisite 10A (C10A) & 3.71 & 2.38 & \\
\hline 7 & C10A-3wt\% & 2.60 & 3.40 & 42.60 \\
\hline 8 & C10A-5wt\% & 2.56 & 3.45 & 44.69 \\
\hline 9 & C10A-8wt\% & 2.57 & 3.43 & 44.10 \\
\hline 10 & C10A-10wt\% & 2.57 & 3.43 & 44.15 \\
\hline 11 & Cloisite 15 (C15) & 2.58 & 3.42 & \\
\hline 12 & C15-3wt\% & 2.47 & 3.58 & 4.70 \\
\hline 13 & C15-5wt\% & 2.43 & 3.63 & 6.19 \\
\hline 14 & C15-8wt\% & 2.44 & 3.63 & 6.04 \\
\hline 15 & C15-10wt\% & 2.45 & 3.60 & 5.31 \\
\hline 16 & Cloisite 93A (C93A) & 3.47 & 2.55 & \\
\hline 17 & C93A-3wt\% & 2.45 & 3.60 & 41.31 \\
\hline 18 & C93A-5wt\% & 2.46 & 3.60 & 41.06 \\
\hline 19 & C93A-8wt\% & 2.48 & 3.57 & 39.89 \\
\hline 20 & C93A-10wt\% & 2.47 & 3.58 & 40.51 \\
\hline
\end{tabular}

